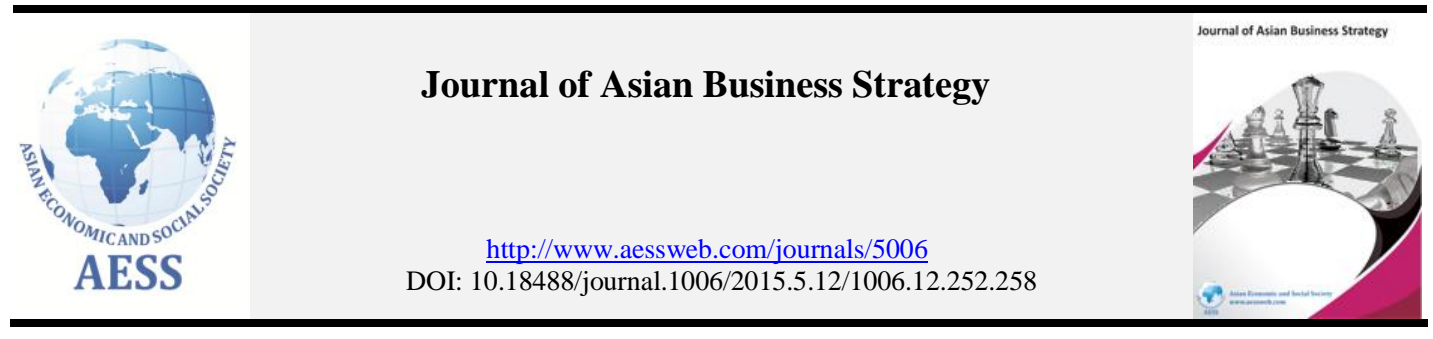

\title{
BASEL ACCORD AND BANKING COMPETITIVITY
}

\author{
Lassaad Jebali \\ International and Regional Integration Laboratory (FSEGT), Tunisia
}

Siwar Hmedi

ISG, Tunis, Tunisia

\section{Article History:}

Received: 15 October 2015

Revised received: 8

November 2015

Accepted: 14 December 2015

Online available: 9

January 2016

Keywords:

Basel,

banking competitivity,

Basel committee

Abstract
The first Basel Accord 1988 focused on the adoption of fixed minimum
capital requirements, which led some banks to maintain higher capital
ratios than they deserve some other banks succeeded in limiting risk-
taking relative to capital as intended. Banks which didn't succeed the
risk management have been able to take actions to reduce their
effectiveness, either by shifting to riskier assets within the same
weighting band or through capital arbitrage. It looks at two possible side
effects. Firstly, whether in some periods capital requirements may have
had the effect of constraining bank lending thereby causing a credit
crunch. Secondly, the introduction of fixed minimum requirements for
banks affected competitiveness with relative forms of intermediation.

\section{INTRODUCTION}

Basel accords are a set of agreements together they form a prudential framework, which treat essentially banking supervision and these are formulated by Basel Committee.

The Basel Committee was established in 1974, the members of this committee are the central-bank governors of thirteen countries (G10).

The Committee is not a formal supranational supervisory authority and do not have legal force. Its only mission is to formulate broad supervisory standards and guidelines, in order to enhance the quality of banking supervision worldwide.

The Basel scope application is very accurate, these agreements are not applied on none descript companies. However it may apply on banks, insurance entities and commercial entities. Till now Basel Committee had published three reforms, however in this report we will focus on the second framework and its impact in matter of credit risk on banks and other types of companies. "What is the impact of Basel II on $\mathrm{t}$ banks in matter of credit risk?"

Corresponding author's

Name: Lassaad Jebali

Email address: Lassaad.jebali@gmail.com 


\section{Section 1: Basel I}

Basel I is a prudential framework in effect since 1988, this accord stands for its simple application and for its significant capital reduction with little or no risk transfer.

This prudential framework is based on a solvency ratio: Cooke Ratio $=\frac{\text { Capital }}{\text { Risk weighted asset }}=8 \%$.

The risk weighted assets under Basel II, include only risk credit and market risk.

\section{Section 2: Basel II}

Basel II is a very complex accord but it is characterized by enhanced risk sensitivity, this second accord was published June 2006. Actually this agreement treats banks unequally, depending on their sophistication of risk management systems and their risk quality.

Basel II is based on a new solvency ratio: McDonough Ratio $=\frac{\text { Capital }}{\text { Risk weighted asset }}=8 \%$.

The new innovation under this solvency ratio is that the risk asset includes one more new risk "Operational risk".

Basel committee introduced the second accord in order to combat regulatory arbitrage and especially to improve Bank risk management.

\subsection{Structure}

Basel II is based on 3 complementary pillars that cannot be dissociated:

\subsubsection{Pillar 1: Regulatory capital charges}

This pillar treat regulatory capital requirement based on three risks:

Credit market and operational risk, add to that this first one, aims for reducing failure risk by cushioning against losses and for providing a continue access to financial markets to meet liquidity needs.

\subsubsection{Pillar 2: Supervision}

Basel II consider supervision is necessary, that's why under this pillar the Basel committee require a qualitative supervision by regulators of internal bank risk control and capital assessment process.

The purpose of banking supervision is first of all, to ensure that banks operate in a safe and sound manner, and secondly to guarantee that the capital and reserves they hold are enough to support the risks that arise in their business.

\subsubsection{Pillar 3: Market discipline}

Under this pillar Basel II recognise that market discipline has the potential to reinforce capital regulation and other supervisory efforts to promote safety and soundness in banks and financial systems. Market discipline imposes strong incentives on banks to conduct their business in a safe, sound and efficient manner. It can also provide a bank with an incentive to maintain a strong capital base as a cushion against potential future losses arising from its risk exposures. ${ }^{2}$

\subsection{Key concepts in matter of credit risk}

\subsubsection{Standard approach (SA)}

The standardised approach is a new method to measure credit risk, even though this approach is not sophisticated but generally generates a high regulatory capital burdens.

\subsubsection{Internal rating based approach (IRB)}

The internal rating based approach allows banks and companies to measure credit risk by using regulatory mathematic formulas based on some internal inputs:

- Probability of default (PD)

- $\quad$ Loss given default (LGD)

\footnotetext{
${ }^{2}$ Basel Committee on Banking Supervision Consultative Document
} 
- $\quad$ Exposure at default (EAD)

- Maturity (M)

This approach provides a better risk sensitive capital requirement, more differentiation in required capital between safer and riskier credits.

Under Basel II, Banks can take the initiative to move to IRB status by improving risk management systems.

\section{Section 3: Incidence of Basel II on BIAT, other banks and different types of firms}

New needs appeared after the introduction of Basel I. This put the light on the establishment of a new, more complicated system of credit risk management.

Besides treating of the impact of Basel on banks generally, we would like to take a sample of a Tunisian bank: Tunisian International Arab Bank (BIAT).

BIAT is where I performed a three months training. This front organisation was founded by Mansour Moalla in 1976, in the meantime it is under the direction of Ismail Mabrouk and Mohamed Agerbi. This credit institution belongs to the first twenty institutions in the North of Africa, and more importantly it is the largest private sector bank in Tunisia.

\section{SIMULATION MODEL PRESENTATION}

To align with international rules of credit risk management, the Arab International Bank of Tunisia "BIAT" who still adapt the old reform, will attempts to establish the new accord Basel II. In this context, we will try to analyse the impact of Basel II on BIAT, other banks and other types of companies.

To estimate this impact, in this report, we will opt for simulation model. Our outputs are the capital requirements and the risk weighted asset and inputs PD, LGD, EAD, and M. In order to represent what can become a reality, we chose to make a calculator VBA under Excel which resumes the mathematic formulas (annex1). Through this calculator we are able to estimate the outputs of our simulation (interface: annex 4).

To facilitate the simulation, the choices of our inputs are the following:

- EAD: $100 \%$

- Maturity (M): 2.5 years

- PD: (annex 2)

- LGD: TPE: $46.2 \%$, PME: $35 \%$ and GE: $38.8 \%$

- LGD under IRB-F: $45 \%$.

So that we can distinguish the impact of Basel II on banks, we have to present the outputs under the old reform (Basel I).

Basel I require a Level of regulatory capital charges equal to $8 \%$ for all banks, as for the risk weighted asset is set by $100 \%$. These outputs are set without discrimination, regardless banks rating and regardless their arranged safety.

\subsection{Incidence of Basel II under standardised approach}

\subsubsection{Regulatory capital requirement}

According to the results we have reached, we synthesized the graphics and tables below, in order to highlight the impact of the standard approach. 


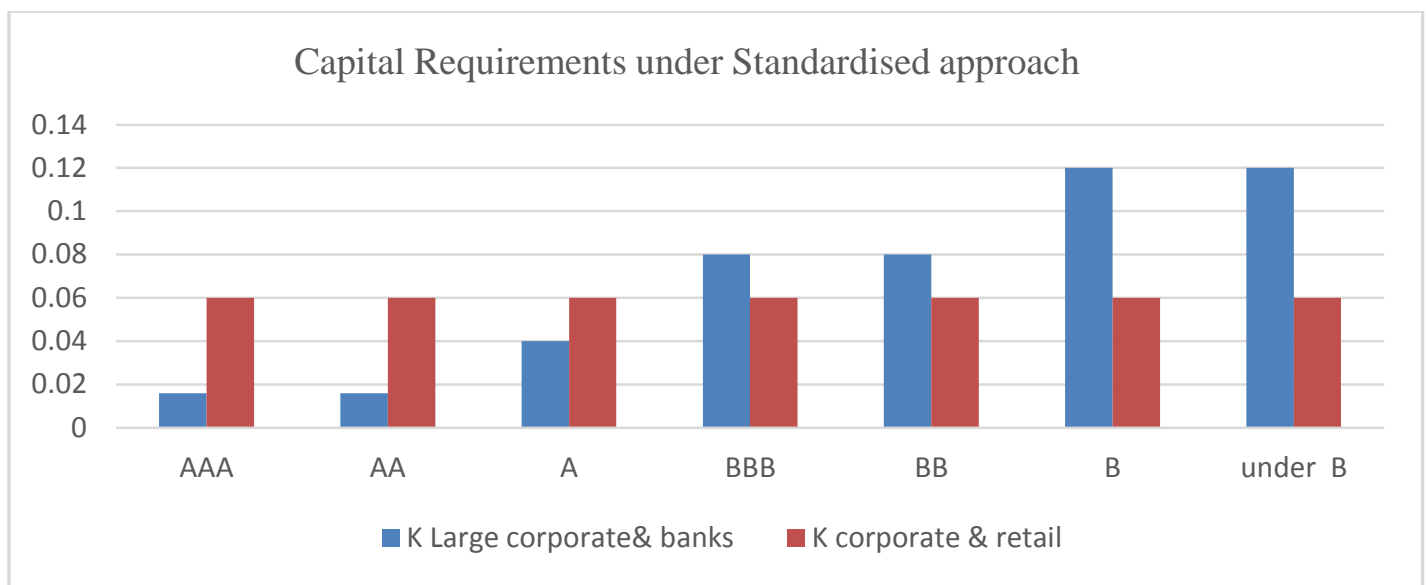

Figure 1: Capital requirements under standardised approach of Basel II

Concerning the corporate and retail companies, the standardized approach offer a lower level of capital charges ( $6 \%$ instead of $8 \%$ ) but this level is provided regardless the rating of these companies and without considering their risk quality. As an example a corporate company with AAA rating, deserve a lower level of capital requirement than a B corporate.

Speaking of large corporate and banks, these types of companies under the Standardized approach are given a sensitive capital charges. Where each type of these companies are required to immobilize a level of their capital that suits their risk management. Excellent the rating is, least is the level of capital charges.

However this approach is a double edged weapon, cause even though it provides lower regulatory capital requirements for some companies, but also it punishes the one with a bad rating by a much highest level of capital charges (12\% instead of $8 \%$ ).

Regarding the BIAT, which stands for its BB rating, we note that this Tunisian bank under this approach will still be forced to immobilize the same level of its capital $8 \%$.

\subsubsection{Risk weighted asset}

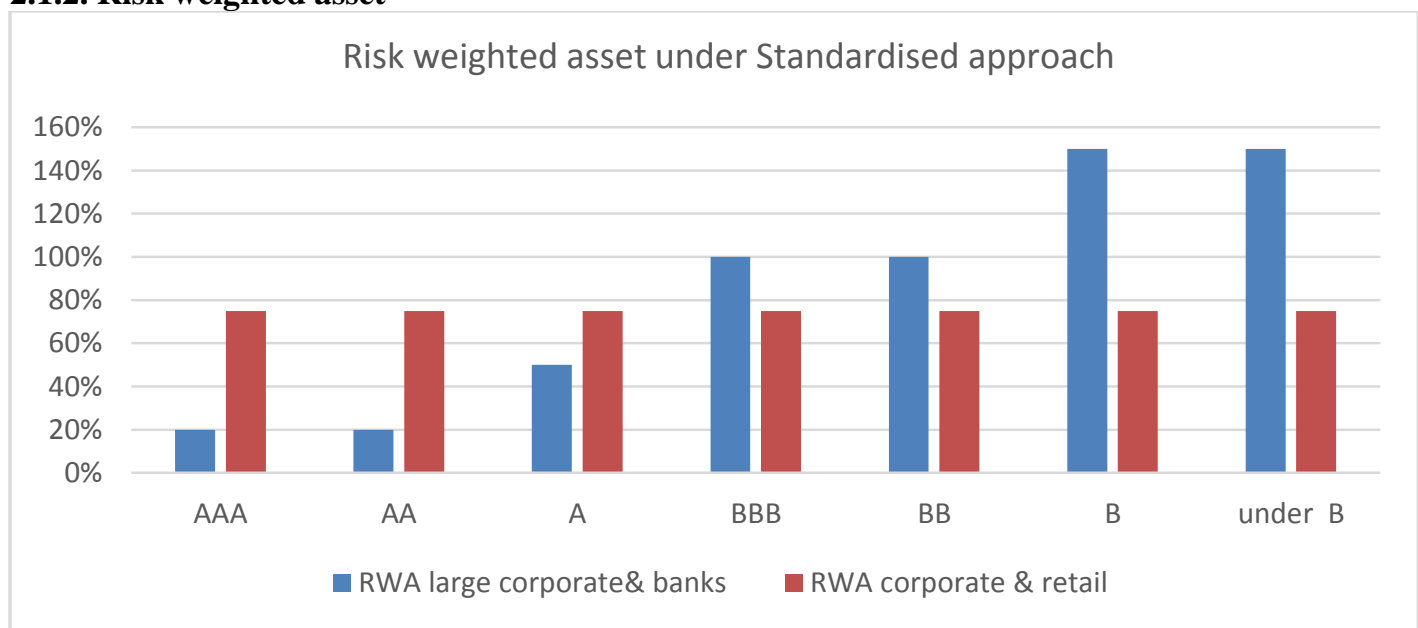

Figure 2: Risk weighted asset under Basel II

The graphic above, resume the new risk weighted asset under Standardized approach for different types of companies. Looking at the weighted risk asset of corporate and retail, we remark a lower level $(75 \%)$ but yet there is no rating discrimination between these companies. 
As for large companies and Banks, Basel II offer to the companies with an excellent rating, a percentage that can go under $20 \%$ instead of $100 \%$ under Basel I, yet offer a percentage up to $150 \%$ for those with a bad rating. However the standard approach has no impact on the Tunisian Bank (BIAT), in fact the risk weighted asset remains $100 \%$.

\subsection{Incidence of Basel II under internal rating based approach}

According to the results we have reached, we synthesized the graphics and tables below, in order to highlight the impact of the internal rating based approach.

\subsubsection{Regulatory capital requirement}

Table 1: Regulatory capital requirements under the internal rating based approach

\begin{tabular}{cccc}
\hline Notes & K Large corporate\& Banks & K Corporate & K Retail \\
\hline 1 & 0.060 & 0.005 & 4.204 \\
2 & 0.011 & 0.010 & 0.000 \\
3 & 0.020 & 0.018 & 0.000 \\
4 & 0.031 & 0.028 & 0.000 \\
5 & 0.045 & 0.041 & 0.001 \\
6 & 0.073 & 0.066 & 0.004 \\
7 & 0.103 & 0.092 & 0.013 \\
8 & 0.133 & 0.119 & 0.028 \\
9 & 0.161 & 0.144 & 0.047 \\
10 & 0.187 & 0.170 & 0.078 \\
\hline
\end{tabular}

According to these results above we could synthesize the graphic below.

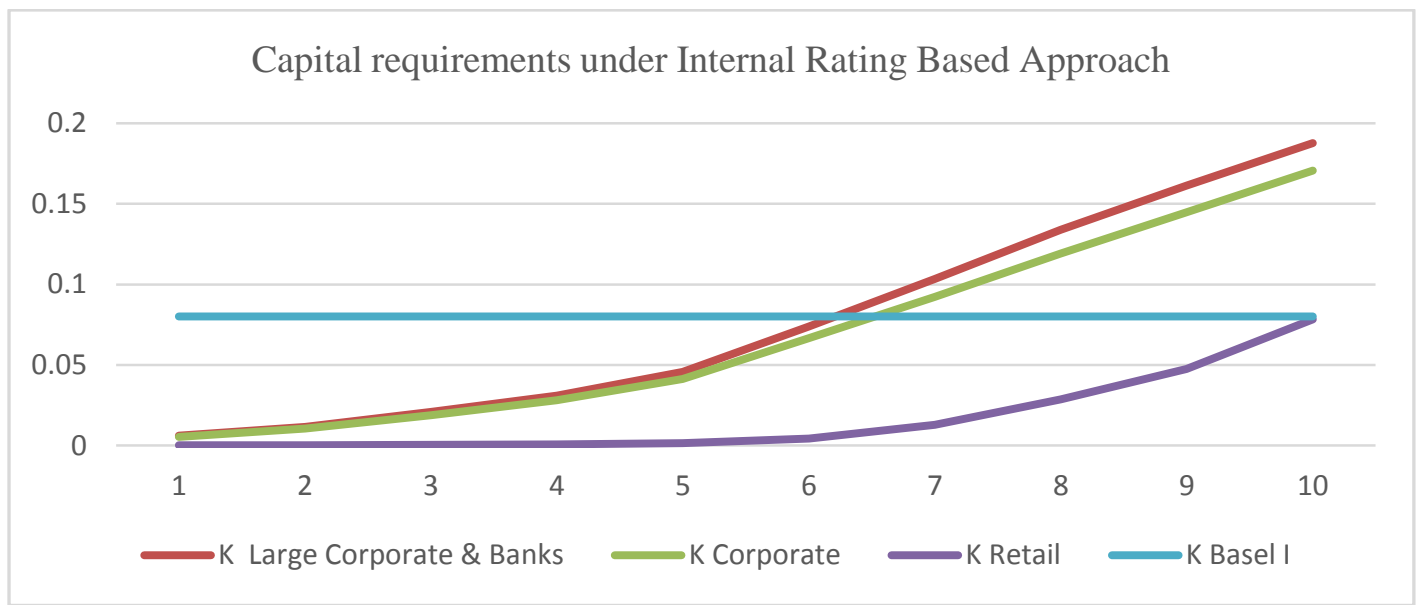

Figure 3: Regulatory capital requirements under the internal rating based approach

The internal rating based approach follow the same logic but stands for its highest risk sensitivity; it treats already the retail and the corporate separately. Moreover this approach offers each company and each bank a capital charges that deserve their note.

Basel II gives the opportunity to the Tunisian Bank (BIAT) with a rating equal to 5, to provide only $4.5 \%$ of its regulatory capital instead of $8 \%$. The internal rating based approach expects that only with half of the capital requirements, the BIAT can cope with financial crises and yet remain solvent. This released gap allows the BIAT, to upgrade its internal resources so that the application of Basel II will be compatible and practicable and also to expand its product range. 


\subsubsection{Risk weighted asset}

Table 2: Risk weighted asset under the internal rating based approach

\begin{tabular}{lccc}
\hline Note & RWA large corporate \& banks & RWA corporate & RWA retail \\
\hline 1 & 0.066 & 0.052 & 0.000 \\
2 & 0.127 & 0.101 & 0.001 \\
3 & 0.230 & 0.182 & 0.004 \\
4 & 0.343 & 0.272 & 0.008 \\
5 & 0.504 & 0.401 & 0.017 \\
6 & 0.816 & 0.648 & 0.052 \\
7 & 1.143 & 0.897 & 0.161 \\
8 & 1.479 & 1.158 & 0.358 \\
9 & 1.783 & 1.408 & 0.592 \\
10 & 2.074 & 1.659 & 0.978 \\
\hline
\end{tabular}

The last innovation of this approach is that it reduces the weighted risk assets for those with an excellent rating, the percentage can be cancelled $(0 \%)$ for those with 1 rating or can go up to $200 \%$ for those with a bad rating (10). We remark high risk sensitivity.

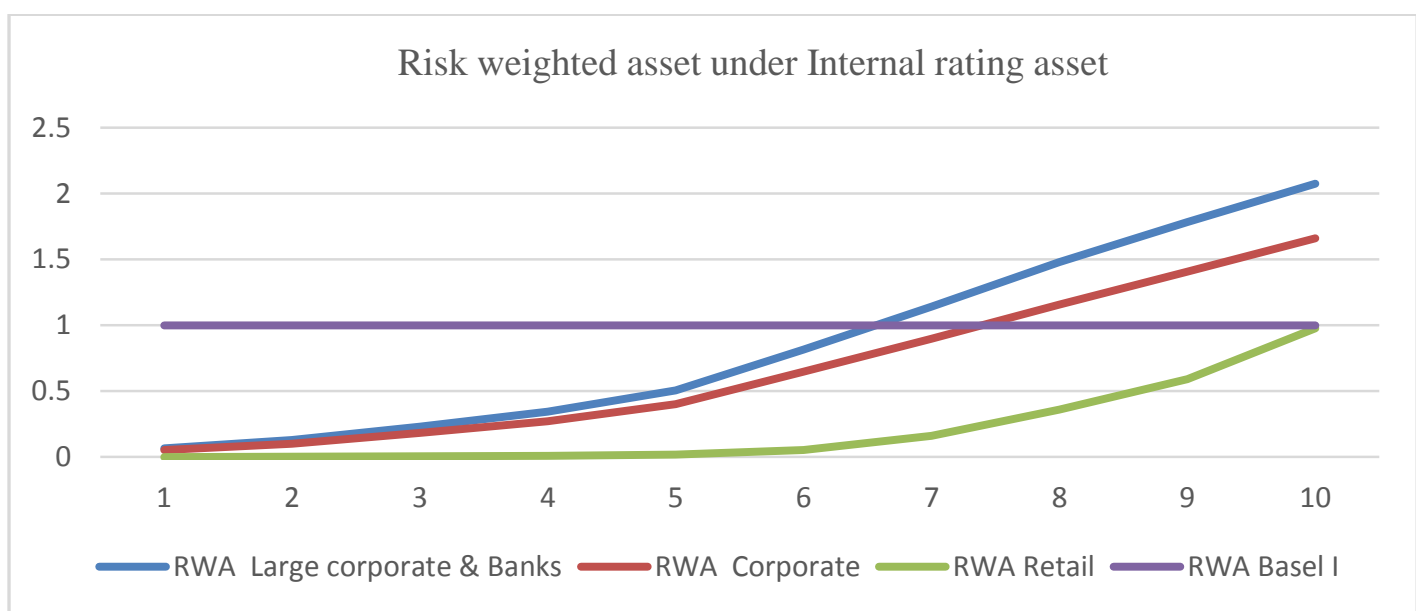

\section{Graphic 4: Risk weighted asset under the internal rating based approach}

Concerning the BIAT (rating = 5), under Basel II its weighted risk assets will be equal to $50 \%$ instead of $100 \%$. To sum up, this approach reduces the risk weighted rates, besides it allows a remarkable economy of capital.

It should be kept in mind that these conclusions could be obtained on the base of theoretical inputs. Apart from the classification and optimization of capital, we note that the introduction of Basel II also affect the structural and organizational plan of any bank.

\section{CONCLUSION}

In order to establish this agreement (Basel II), banks and companies have to adopt more sophisticated risk management systems so they can afford a lower regulatory capital.

It appears from this study that the application of Basel II allows the BIAT to save capital requirement and reduce the risk weights compared to Basel I, whatever the method (Standard or IRB), and as a result this agreement will profoundly alter Banks behaviour. 


\section{Annexes1: Regulatory formulas}

Regulatory Capital requirements formulas

- Coporate :

$$
K=\left(\operatorname{LGD} * \phi\left(\frac{1}{\sqrt{1-\mathrm{R}^{2}}} \phi(\mathrm{PD})+\frac{\mathrm{R}}{\sqrt{1-\mathrm{R}^{2}}} \phi^{-1}(0.999)\right)-P D * L G D\right) * \frac{1+(M-2.5 * b(P D)}{(1-1.5 * b(P D)}
$$

- Retail:

Where :

$$
K=\mathrm{LGD} * \phi\left(\frac{1}{\sqrt{1-\mathrm{R}^{2}}} \phi(\mathrm{PD})+\frac{\mathrm{R}}{\sqrt{1-\mathrm{R}^{2}}} \phi^{-1}(0.999)\right)-0.09 * P D * L G D
$$

$\frac{1+(M-2.5 * b(P D)}{(1-1.5 * b(P D)}:$ Maturity adjustment (Maturity coefficient)

$\mathrm{M}$ : Average commitments maturity(in our case it is equal to 2.5 years)

$\mathrm{b}(\mathrm{PD})=[0.11852-0.05478 * \log (\mathrm{PD})]^{2}$

Risk weighted asset $(\mathrm{RWA})=\mathrm{K}^{*} 12.5^{*} \mathrm{EAD}$

Correlation formulas :

- Large Corporate :

- Corporate:

$$
R^{2}=0.12 * \frac{1-e^{(-50 * P D)}}{2-e^{-50}}+0.24 *\left[1-\frac{1-e^{-50 * P D}}{1-e^{-50}}\right]
$$

$R^{2}=0.12 * \frac{1-e^{(-50 * P D)}}{2-e^{-50}}+0.24 *\left[1-\frac{1-e^{-50 * P D}}{1-e^{-50}}\right]-0.04 *\left[1-\frac{\mathrm{CA}-5}{45}\right]$

- Retail :

$$
R^{2}=0.03 * \frac{1-e^{(-35 * P D)}}{2-e^{-35}}+0.16 *\left[1-\frac{1-e^{-35 * P D}}{1-e^{-35}}\right]
$$

Where CA (turnover) is between 3 and 50 million Dinars

- $\quad \phi(\mathrm{x})$ :Cumulative distribution function for a standard normal random variable. This Normal cumulative function and its inverse is available and written in Excel (or worksheet Function. Norm SDist SINV)

\section{Annex 2: Probability of default (Standard \& Poors)}

\begin{tabular}{lccc}
\hline & Note & Comment & Probability of default (PD) \% \\
\hline & 1 & Excellent & 0.01 \\
Investment & 2 & Very good & 0.03 \\
Grade & 3 & Good & 0.08 \\
& 4 & Above avarage & 0.16 \\
& 5 & Avarage & 0.33 \\
Non & 6 & Below avarage & 1.00 \\
Investment & 7 & Poor & 3.07 \\
Grade & 8 & Weak & 6.82 \\
& 9 & Speculative & 11.27 \\
& 10 & Substandard & 18.62 \\
\hline
\end{tabular}

Funding: This study received no specific financial support.

Competing Interests: The authors declare that they have no conflict of interests.

Contributors/Acknowledgement: All authors participated equally in designing and estimation of current research.

Views and opinions expressed in this study are the views and opinions of the authors, Journal of Asian Business Strategy shall not be responsible or answerable for any loss, damage or liability etc. caused in relation to/arising out of the use of the content. 